\title{
Increased Pontin expression is a potential predictor for outcome in sporadic colorectal carcinoma
}

\author{
JOHANNES C. LAUSCHER ${ }^{1}$, SEFER ELEZKURTAJ ${ }^{2}$, SONJA DULLAT $^{1}$, SYBILLE LIPKA $^{3}$, \\ JÖRN GRÖNE ${ }^{1}$, HEINZ J. BUHR ${ }^{1}$, OTMAR HUBER ${ }^{4}$ and MARTIN KRUSCHEWSKI ${ }^{1}$
}

\begin{abstract}
Departments of ${ }^{1}$ General, Vascular and Thoracic Surgery, ${ }^{2}$ Pathology and ${ }^{3}$ Ophthalmology, Charité-Universitätsmedizin Berlin, Campus Benjamin Franklin, Hindenburgdamm 30, D-12200 Berlin; ${ }^{4}$ Institute of Biochemistry II, Jena University Hospital, Friedrich-Schiller-University Jena, Nonnenplan 2, D-07743 Jena, Germany
\end{abstract}

Received April 6, 2012; Accepted June 20, 2012

DOI: $10.3892 /$ or.2012.1968

\begin{abstract}
Colorectal cancer is one of the leading causes of cancer-related death worldwide. Molecular biomarkers could help to predict patient outcome and to identify patients who benefit from adjuvant therapy. Pontin and Reptin are ATPases which are involved in transcriptional regulation, DNA damage repair and regulation of cell proliferation. Many interaction partners of Pontin and Reptin such as $\beta$-catenin and c-myc are important factors in carcinogenesis. We hypothesized that Pontin and Reptin expression may be a negative predictor for survival in colorectal carcinoma. Specimens from 115 patients with primary colon adenocarcinomas UICC stage III and primary rectal adenocarcinomas UICC stage II and III curatively resected at the Department of Surgery, Charité Berlin, were evaluated. Clinical follow-up data were complete and mean follow-up time of patients was 51.8 months. We evaluated the expression of Pontin, Reptin and Ki-67 by immunohistochemistry. Patients with Pontin-positive carcinomas showed no differences in recurrence-free survival $(\mathrm{P}=0.109)$ and overall survival $(\mathrm{P}=0.197)$. There were no differences in Reptin-positive carcinomas and $\mathrm{Ki}$-67-positive carcinomas in recurrence-free survival $(\mathrm{P}=0.443$ and $\mathrm{P}=0.160)$ and overall survival ( $\mathrm{P}=0.477$ and $\mathrm{P}=0.687$ ). Patients with Pontin-positive colorectal carcinomas receiving adjuvant therapy had a significantly worse recurrence-free survival $(\mathrm{P}=0.008)$ and overall survival $(\mathrm{p}=0.011)$ than Pontin-negative patients with adjuvant therapy. In UICC stage III, Pontin-positive colorectal carcinomas had a significantly worse recurrence-free survival $(\mathrm{P}=0.028)$. Pontin-positivity seems to be a negative predictor for response to adjuvant therapy in colorectal cancer patients
\end{abstract}

Correspondence to: Dr Johannes C. Lauscher, Department of General, Vascular and Thoracic Surgery, Charité Campus Benjamin Franklin, Hindenburgdamm 30, D-12200 Berlin, Germany

E-mail: johannes.lauscher@charite.de

Key words: Pontin, Reptin, colorectal cancer, prognosis, adjuvant therapy and may help to identify patients with adverse outcome in advanced tumor stages.

\section{Introduction}

Colorectal cancer is the third most common cancer in both genders in the Western world (1). The 5-year survival rates reported for patients with stage II and III colorectal cancer vary between 92 and 67\% (SEER Cancer Statistics). Patients with UICC stage III carcinomas will benefit from adjuvant chemotherapy in only $5-15 \%$ and many patients who undergo adjuvant therapy will be overtreated $(2,3)$. Colorectal cancer is considered relatively resistent to chemotherapy (4). Various chemotherapeutic approaches have only led to a moderate decline in mortality. Therefore, additional parameters such as molecular biomarkers are needed to predict which patients will benefit from adjuvant treatment.

Pontin (also called RuvBl1 and TIP49a) and Reptin (also called RuvB12 and TIP49b) belong to the family of AAA+ATPases (ATPases associated with various cellular activities). The Pontin gene is located on chromosome $3 q 21$, while the Reptin gene is located on chromosome 19q13.3 $(5,6)$. Pontin and Reptin are normally coexpressed and frequently share common binding partners. They are associated with several types of high molecular weight complexes involved in many cellular activities such as transcription regulation, chromatin remodeling, DNA damage repair and regulation of cell proliferation $(7,8)$.

Numerous Pontin and Reptin interaction partners have known roles in cancer (8). Pontin and Reptin modulate the transcriptional activities of the oncogene $\beta$-catenin. By directly binding to $\beta$-catenin, Pontin enhances the transcriptional activity of the TCF/LEF-1/ $\beta$-catenin-transcription complex and the transcription of target genes such as cyclin D1, c-myc, and VEGF-A which may promote tumor progression and metastasis $(5,6,9)$. It was shown by reporter gene assays that the two proteins behaved antagonistically, with Pontin enhancing, and Reptin repressing TCF/LEF- $1 / \beta$-catenin transcriptional activity $(6,10-12)$. Reptin also cooperates with $\beta$-catenin in suppressing the expression of the anti-metastatic gene KAI-1 (13). $\beta$-catenin signaling is activated in a number of cancers e.g. colorectal cancer and HCC. 
Pontin and Reptin directly bind the c-myc oncogene (14-16). All the reported effects favor c-myc oncogenic effects. Interaction leads to growth promotion through transcriptional repression of the growth inhibitory p21 gene (14), to defects in cell adhesion (16), or to repression of tumor suppressor genes (17).

Reptin and Pontin have been implicated in DNA repair. They are both members of the Tip60 histone acetyltransferase complex. Tip60 plays multiple roles in DNA damage response (18) and is involved in DNA damage-induced apoptosis (19). Pontin seems to be required for Tip60 activity after DNA damage (20).

Pontin also seems to act as an anti-apoptotic factor. A dominant-negative mutant of Pontin without ATPase activity potentiates the apoptotic activity of c-myc (21). It was shown that the knockdown of Pontin or Reptin in HCC cells led to spontaneous apoptosis (22). Altogether, Pontin and Reptin favor cell proliferation and inhibit apoptosis, properties well in line with their supposed roles in cancer.

Taken together, Pontin and Reptin interact with many established actors of carcinogenesis and they are both involved in processes that favor tumor progression.

$\mathrm{Ki}-67$ is a nuclear protein that is associated with cellular proliferation and ribosomal RNA transcription (23). The $\mathrm{Ki}-67$ protein is a cellular marker for proliferation (24). Ki-67 is present during all active phases of the cell cycle $\left(\mathrm{G}_{1}, \mathrm{~S}, \mathrm{G}_{2}\right.$, and mitosis), but is absent from resting cells $\left(\mathrm{G}_{0}\right)$. Ki-67 is not an independent predictor of outcome in colorectal cancer $(25,26)$. Ki-67 expression as a marker of cell proliferation was evaluated to rule out the epiphenomenon that a potential Pontin or Reptin overexpression is just a sign of enhanced cell proliferation in tumors.

We showed before in 34 patients that Pontin expression is higher in colorectal carcinoma than in normal colorectal mucosa (27). An association of Pontin and Reptin expression with the prognosis of colorectal cancer patients and response to adjuvant therapy was not reported before.

Here, we report the expression of Pontin, Reptin and Ki-67 on the protein level in a prospective cohort of patients with colorectal carcinomas stage II/III and evaluate the prognostic significance as well as the influence on the outcome after adjuvant therapy.

\section{Patients and methods}

Study population and tissue samples. In this study, specimens from 115 patients with curatively resected colorectal carcinomas at the Department of Surgery, Charité Campus Benjamin Franklin, Berlin, between 1995 and 2001 were evaluated. Elective surgery was performed according to standardized procedures for CRC with systematic lymphadenectomy and total mesorectal excision for carcinomas of the rectum. Representative samples from the resected colorectal cancer tissue and normal tissues were paraffin-embedded and formalin fixed for routine work up in the Department of Pathology, Charité Campus Benjamin Franklin, Berlin.

Only patients with primary colon adenocarcinomas UICC stage III and primary rectal adenocarcinomas UICC stage II and III and no other known malignancies and no preoperative radiochemotherapy were included. The tissue specimens consisted of 37 colon carcinomas and 78 rectum carcinomas as well as adjacent normal mucosa. Tissue samples were fixed in $4 \%$ neutral buffered formaldehyde, embedded in paraffin and histopathological evaluation was performed on standard hematoxylin and eosin sections.

The stage of tumors was assessed according to the UICC staging system. Tumor differentiation was determined according to the WHO guidelines. For all patients a minimum of 12 lymph nodes were investigated. Clinical follow-up data were available for all patients. The mean follow-up time of patients was $51.8 \pm 2.5$ months.

Data on postoperative chemotherapy are known from 113 patients and on radiotherapy in 112 cases. Patients were treated according to the guidelines of the German Cancer Society at that time. Thus, patients with colon cancer UICC stage III were administered chemotherapy (5-FU/folic acid). Postoperative radiochemotherapy (5-FU/folic acid and radiation doses of $45 \mathrm{~Gy}$ ) was administered to patients with rectal carcinomas in UICC stage II and III.

Immunohistochemistry. For immunostaining of paraffinembedded tissues, $4 \mu \mathrm{m}$ thick sections were cut, deparaffinized, and subjected to a heat-induced epitope retrieval step. Endogenous peroxidase activity was blocked with $1 \%$ (v/v) hydrogen peroxide in distilled water. To block unspecific binding, the sections were incubated with $1 \mathrm{X}$ PowerBlock (BioGenex Inc., San Ramon, CA, USA) for 5 min. Subsequently samples were incubated with Protein A-Sepharose purified mouse monoclonal anti-Pontin (5G3-11) antibody (generated in our laboratory) $(0.44 \mathrm{mg} / \mathrm{ml})$ diluted 1:100 in PBS for $30 \mathrm{~min}$ at $37^{\circ} \mathrm{C}$. The immunohistochemistry for Reptin was done analogously with mouse monoclonal anti-Reptin (E9-5) antibody $1.8 \mu \mathrm{g} / \mathrm{ml}$ diluted 1:50 in PBS for $30 \mathrm{~min}$ at $37^{\circ} \mathrm{C}$. For Ki-67 staining, monoclonal mouse anti-human Ki-67 antibodies (Isotype IgG1 kappa, clone MIB-1; Dako, Hamburg, Germany) were detected using the streptavidin biotin-alkaline phosphatase method with Fast Red as chromogen according to the manufacturer's recommendations (Dako), using an automated immunostainer (TechMate 500; Dako).

Sections were analysed by standard light microscopy using a Zeiss Axioskop (Carl Zeiss, Jena, Germany). Stained tumor cell nuclei were counted and semi-quantitatively evaluated. The immunoreactivity of Pontin and Reptin was categorised in negative expression $(<10 \%$ stained tumor cell nuclei) and positive expression ( $\geq 10 \%$ stained tumor cell nuclei) in 115 sections. The immunoreactivity of Ki-67 was categorised in negative expression ( $<30 \%$ stained tumor cell nuclei) and positive expression ( $\geq 30 \%$ stained tumor cell nuclei) in 69 sections. For each analysis, a minimum of five high power fields (HPF) $\left(0.237 \mathrm{~mm}^{2}\right)$ were analysed and the mean percentage of nuclear staining was noted. All slides were evaluated independently by an experienced pathologist (S.E.) and the first author (J.C.L.), who were blinded to patient outcome. There were only minor discrepancies in the evaluation. Discordant cases were re-evaluated on a multi-head microscope until a final decision was reached.

Statistical analysis. The statistical significance of the association between Pontin, Reptin and Ki-67 as well as 
Table I. Clinicopathological characteristics of 115 patients with colorectal cancer.

\begin{tabular}{lc}
\hline Characteristics & All cases n (\%) \\
\hline pT & \\
pT1 & $2(1.7)$ \\
pT2 & $6(5.2)$ \\
pT3 & $88(76.5)$ \\
pT4 & $19(16.5)$ \\
pN & \\
pN0 & $35(30.4)$ \\
pN1 & $44(38.3)$ \\
pN2 & $27(23.5)$ \\
pN3 & $9(7.8)$ \\
Histological grade & \\
G1 & $1(0.9)$ \\
G2 & $54(47.0)$ \\
G3 & $60(52.2)$ \\
UICC stage & \\
II & $35(30.4)$ \\
III & $80(70.6)$ \\
Location & \\
Colon & $37(32.2)$ \\
Rectum & $78(67.8)$ \\
\hline
\end{tabular}

clinico-pathological parameters was assessed by Fisher's exact test. The probability of overall survival as a function of time was determined by the Kaplan-Meier method. Differences in survival curves were compared by the log-rank test. Generally, P-values $<0.05$ were considered significant, hazard ratios are reported with $95 \%$ confidence intervals. For the statistical evaluation IBM SPSS Statistics 18 (Armonk, NY, USA) was used.

\section{Results}

Clinical and pathological characteristics of colorectal carcinomas. Colorectal carcinoma specimens from 115 patients were investigated for immunoreactivity of Pontin, Reptin and Ki-67. The mean age of patients at surgery was 64 years (range, 38-89 years). There were 48 female and 67 male patients. The majority of tumors were diagnosed in tumor stage pT3 (88 cases; 76.5\%). Most carcinomas (60 cases; $52.2 \%$ ) were poorly differentiated. In total, 35 patients (30.4\%) had no lymph node metastasis (pN0), whereas 80 patients $(69.6 \%)$ were node positive. Clinico-pathological features are summarized in Table I.

Expression of Pontin, Reptin and Ki-67in colorectal cancer. Immunohistochemical analysis of Pontin, Reptin was performed on 115 colorectal carcinomas, immunohistochemical analysis of Ki-67 was performed on 69 colorectal carcinomas (Fig. 1). Positive expression of Pontin and Reptin was defined as a nuclear staining reaction in $\geq 10 \%$ of the tumor cells (27). High expression of Ki-67 (above median) was
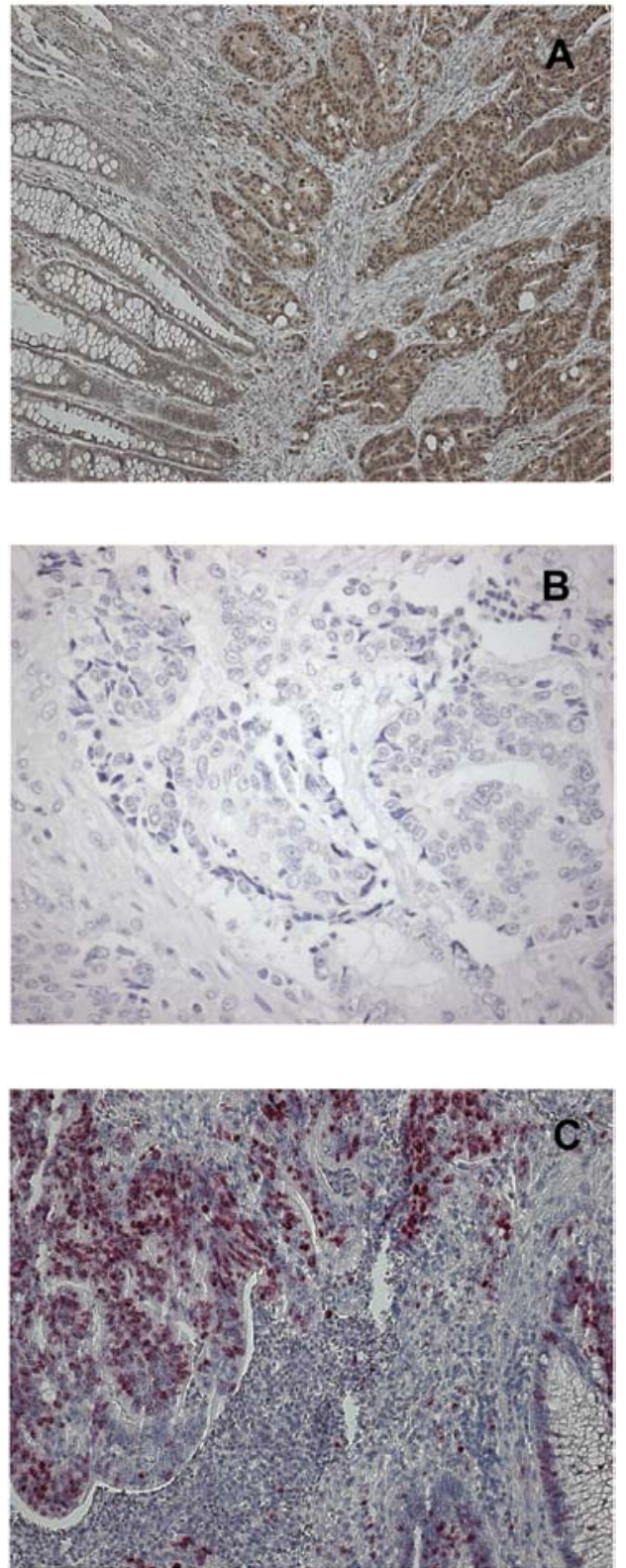

Figure 1. Immunohistochemical staining of Pontin, Reptin and Ki-67 in colorectal cancer tissue. (A) Stronger nuclear Pontin expression in tumor tissue compared with adjacent normal mucosa; (B) weak Reptin expression in tumor tissue; (C) stronger nuclear Ki-67 expression in tumor tissue compared with adjacent normal mucosa. Magnification, x100 (A), x400 (B), x200 (C).

a nuclear staining reaction in $\geq 30 \%$ of the tumor cells. We observed nuclear Pontin expression in 56 carcinomas (48.7\%), and no nuclear Pontin expression in 59 carcinomas (51.3\%). Positive expression of Reptin was found in 28 carcinomas (24.3\%) and negative expression in 87 carcinomas (75.7\%). We observed high nuclear Ki-67 expression in 38 carcinomas (55.1\%), and low nuclear Ki-67 expression in 31 carcinomas (44.9\%).

Relationship between Pontin, Reptin, Ki-67 and survival. In univariate Kaplan-Meier analyses, patients with Pontin-positive carcinomas showed no significant differences in recurrencefree survival $(\mathrm{p}=0.109)$ and overall survival $(\mathrm{P}=0.197)$; (Fig. 2). Patients with Reptin-positive carcinomas showed no 

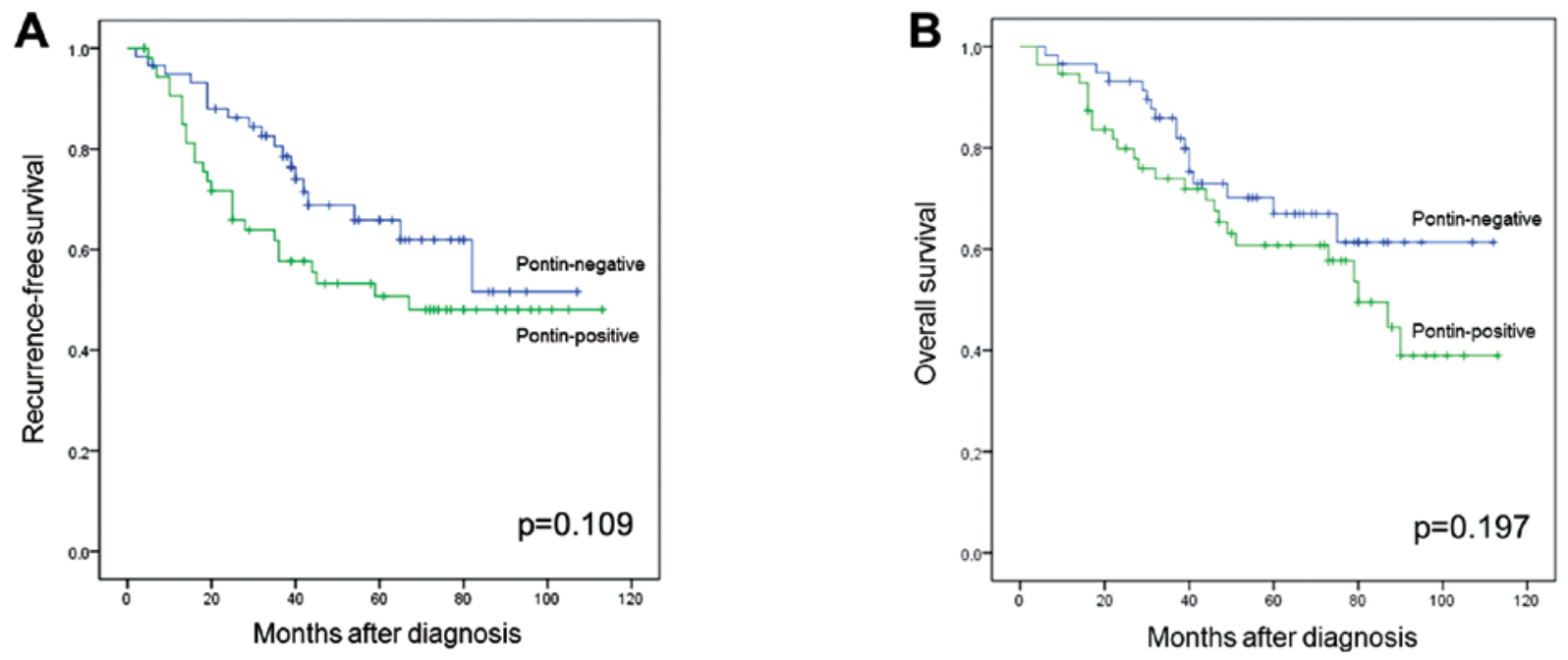

Figure 2. Univariate Kaplan-Meier survival analyses of Pontin-expression and recurrence-free survival (A) and overall survival (B).
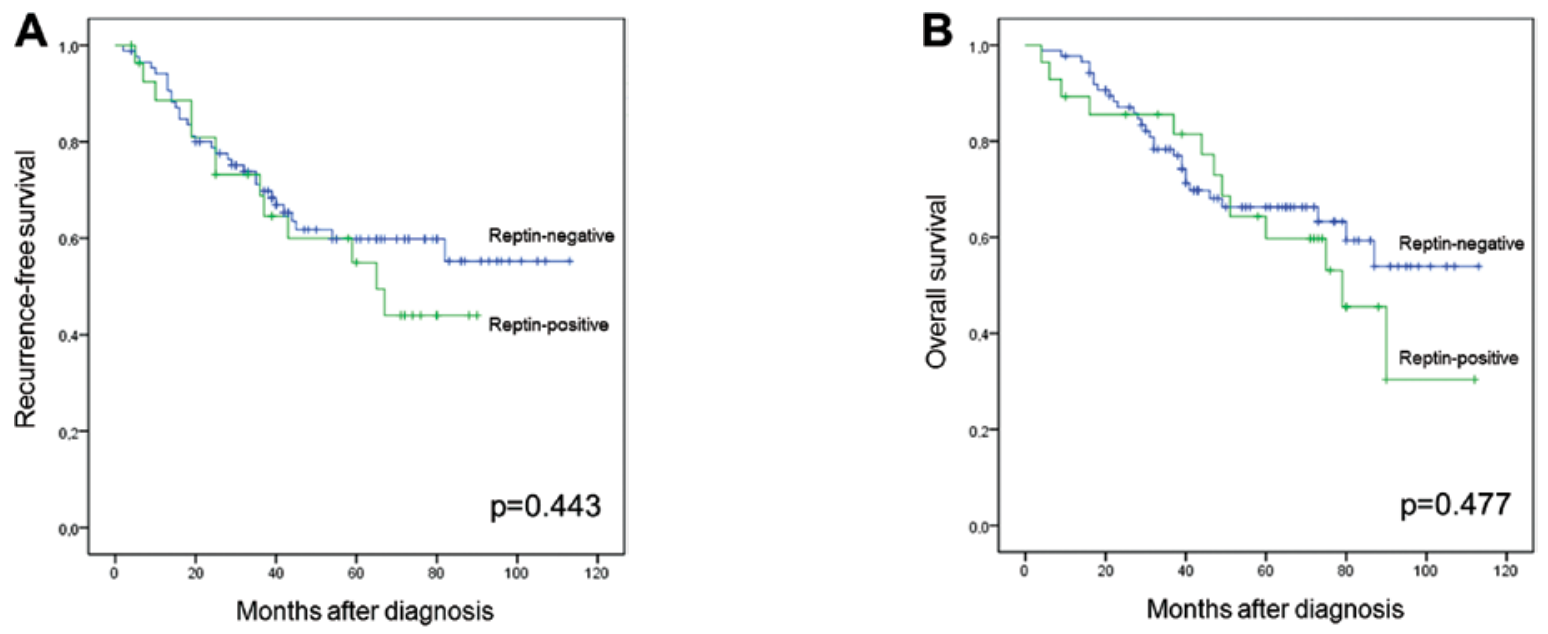

Figure 3. Univariate Kaplan-Meier survival analyses of Reptin-expression and recurrence-free survival (A) and overall survival (B).

A

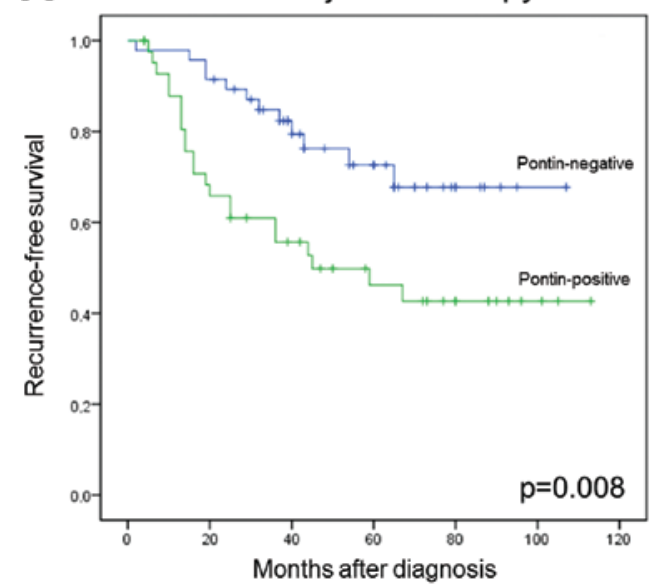

B

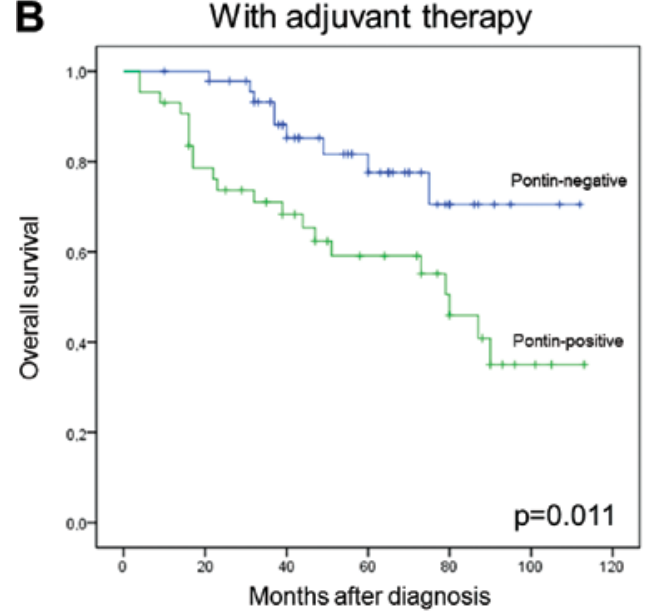

Figure 4. Univariate Kaplan-Meier survival analyses of Pontin-expression and recurrence-free survival (A) and overall survival (B) in patients with adjuvant therapy.

significant differences in recurrence-free survival $(\mathrm{P}=0.443)$ and overall survival ( $\mathrm{P}=0.477)$; (Fig. 3). Patients with Ki-67- positive carcinomas showed no difference in recurrence-free survival $(\mathrm{P}=0.160)$ and overall survival $(\mathrm{P}=0.687)$. 

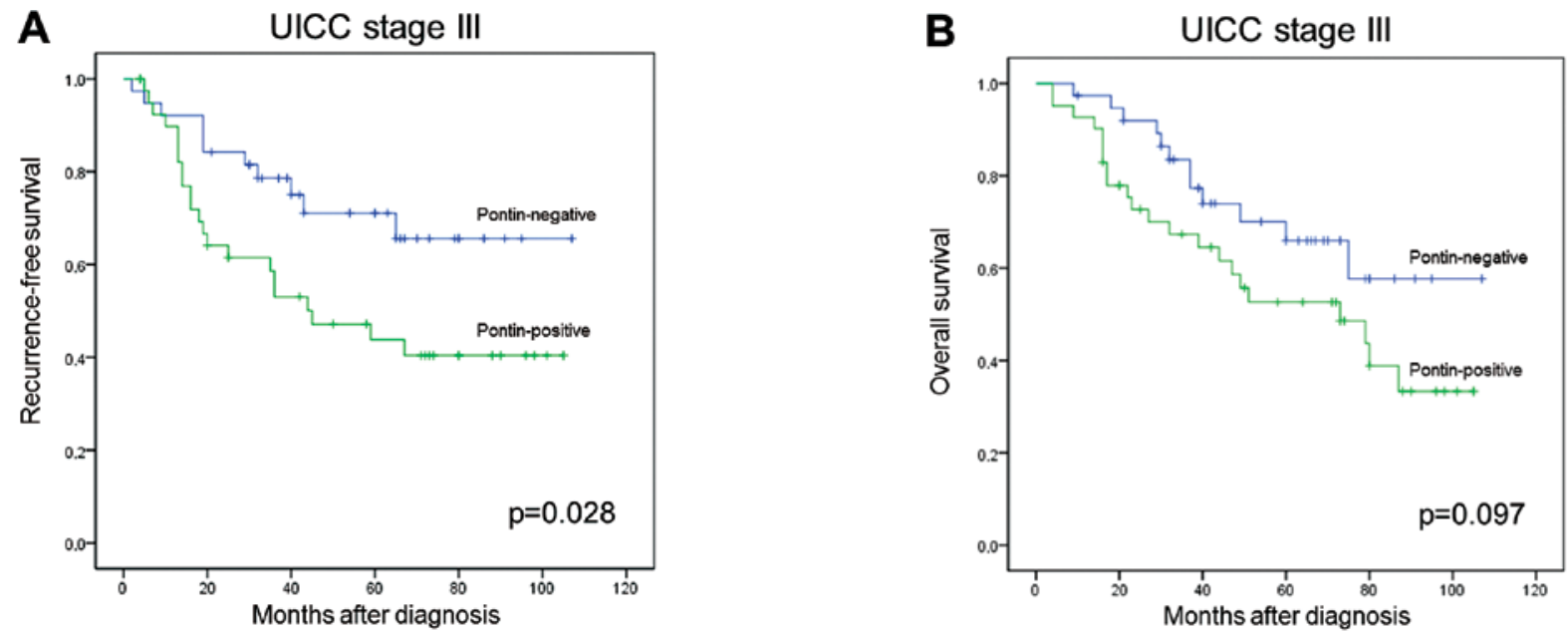

Figure 5. Univariate Kaplan-Meier survival analyses of Pontin-expression and recurrence-free survival (A) and overall survival (B) in patients in UICC stage III.

Relationship between Pontin, Reptin, Ki-67, adjuvant therapy and patient prognosis. Patients with Pontin-positive colorectal carcinomas and adjuvant therapy had a significantly worse recurrence-free survival $(\mathrm{P}=0.008)$ and overall survival $(\mathrm{P}=0.011)$ than Pontin-negative patients with adjuvant therapy (Fig. 4). There was no association between Reptin-positivity and recurrence-free survival $(\mathrm{P}=0.089)$ or overall survival $(\mathrm{P}=0.302)$ after adjuvant therapy. There was no association between $\mathrm{Ki}$-67-positivity and overall survival after adjuvant therapy $(\mathrm{P}=0.205)$. In UICC stage III, Pontin-positive colorectal carcinomas had a significantly worse recurrencefree survival $(\mathrm{P}=0.028)$; the overall survival in UICC stage III was not significantly different $(\mathrm{P}=0.097)$; (Fig. 5). There was no association between Reptin-positivity and Ki-67-positivity and overall-survival in UICC stage III $(\mathrm{P}=0.841$ and $\mathrm{P}=0.824)$.

\section{Discussion}

Pontin and Reptin are involved in many cellular functions such as modulation of transcriptional activities of oncogenes, chromatin remodeling, and DNA damage repair that are highly relevant for carcinogenesis. There is abundant evidence based on in vitro experiments that they may play an important role in carcinogenesis. There is good evidence that Pontin is required for the oncogenic activity of c-myc and $\beta$-catenin $(28,29)$. Still, data on Pontin or Reptin expression in human cancer is sparse.

We have investigated Pontin expression in a series of 34 colon cancer specimens and found it to be increased in more than $80 \%$ of the cases compared to normal mucosa. We detected a nuclear co-localization of Pontin together with $\beta$-catenin (27).

In this study, we hypothesized that alterations in Pontin and Reptin expression may provide prognostic information on colorectal cancer patients, particularly with regard to the adjuvant therapy.

Since their main effects such as modulation of transcription, chromatin remodeling, DNA damage repair and regulation of cell proliferation are located in the cell nucleus, we focussed on the nuclear expression of Pontin and Reptin. Positivity was evaluated according to the nuclear expression of both proteins.
For Reptin, no associations to patient prognosis was detectable. There was no difference in recurrence-free survival or in overall survival for Pontin. But, in the subgroup of patients with adjuvant therapy, Pontin-positive patients had a significantly worse recurrence-free survival $(\mathrm{P}=0.008)$ and overall survival $(\mathrm{P}=0.011)$. Furthermore, in nodal positive colorectal carcinomas (UICC stage III), Pontin-positive colorectal carcinomas had a significantly worse recurrence-free survival $(\mathrm{P}=0.028)$. $\mathrm{Ki}-67$ expression was not associated to patient outcome in any parameter. Hence, Pontin overexpression in tumors is not just a sign of the enhanced mitosis rate in tumor cells. Taken together, Pontin expression may be a negative predictor for response to adjuvant therapy and a negative predictor for adverse outcome in advanced tumor stages in colorectal carcinoma.

This result corresponds to microarray data. An overexpression in gene expression analysis of Pontin and/or Reptin was shown in a variety of human solid tumors such as colorectal (30), gastric (31), bladder (32), and non-small cell lung cancer (33). Furthermore, it was shown that Pontin mRNA is upregulated in human HCC 3.9-fold as compared to non-tumor liver $(\mathrm{P}=0.0004)$. Pontin expression was a strong independent factor of poor prognosis in a multivariate analysis (22).

However, Reptin was also overexpressed and associated to poor prognosis in HCC (34). In the evaluation of Reptin expression in 34 patients with colorectal carcinoma, we could not detect any differences between carcinoma tissue and normal mucosa (27; and our unpublished data). The repression of TCF/LEF-1/ $\beta$-catenin transcriptional activity followed by less activation of target genes of $\beta$-catenin signaling such as c-myc may play a role for the lack of overexpression in colorectal carcinoma (6,10-12).

From our study, however, we cannot draw any conclusions on the molecular mechanisms that are involved in the upregulation of Pontin expression. This either could be mediated at the transcriptional level or by post-translational mechanisms. Data from hepatocellular carcinomas show that Pontin and Reptin protein levels are strictly controlled by a post-translational mechanism involving proteasomal degradation of newly synthesized proteins. A tight regulatory 
interaction between Pontin and Reptin by post-translational mechanism was shown (22).

It has to be further evaluated whether mutations in the Pontin gene can be detected in cancer cells and how these mutations may affect the function or stability of Pontin. Recently, two single nucleotide polymorphisms associated with an increased risk of ovarian cancer were identified in the Pontin gene (35).

Collectively, we show for the first time that Pontin may be a negative predictor for survival in colorectal cancer patients. These results further substantiate many biochemical and cell biological observations indicating that Pontin has an important modulatory role in processes that may contribute to tumorigenesis.

The role of Pontin in carcinogenesis has to be defined more clearly in the future by further elucidating its molecular mechanisms.

\section{References}

1. Jemal A, Siegel R, Ward E, Murray T, Xu J and Thun MJ: Cancer statistics, 2007. CA Cancer J Clin 57: 43-66, 2007.

2. Nehls O, Okech T, Hsieh CJ, Enzinger T, Sarbia M, Borchard F, Gruenagel HH, Gaco V, Hass HG, Arkenau HT, et al: Studies on $\mathrm{p} 53, \mathrm{BAX}$ and $\mathrm{Bcl}-2$ protein expression and microsatellite instability in stage III (UICC) colon cancer treated by adjuvant chemotherapy: major prognostic impact of proapoptotic BAX Br J Cancer 96: 1409-1418, 2007.

3. Mamounas E, Wieand S, Wolmark N, Bear HD, Atkins JN, Song J and Rockette H: Comparative efficacy of adjuvant chemotherapy in patients with Dukes' B versus Dukes' C colon cancer: results from four National Surgical Adjuvant Breast and Bowel Project adjuvant studies (C-01, C-02, C-03 and C-04). J Clin Oncol 17: $1349-1355,1999$.

4. Aneja R, Ghaleh AM, Zhou J, Yang VW and Joshi HC: p53 and p21 determine the sensitivity of noscapine-induced apoptosis in colon cancer cells. Cancer Res 67: 3862-3870, 2007.

5. Bauer A, Huber O and Kemler R: Pontin52, an interaction partner of $\beta$-catenin, binds to the TATA box binding protein. Proc Natl Acad Sci USA 95: 14787-14792, 1998

6. Bauer A, Chauvet S, Huber O, Usseglio F, Rothbächer U, Aragnol D, Kemler R and Pradel J: Pontin52 and reptin52 as antagonistic regulators of beta-catenin signalling activity. EMBO J 19: 6121-6130, 2000.

7. Grigoletto A, Lestienne P and Rosenbaum J: The multifaceted proteins Reptin and Pontin as major players in cancer. Biochim Biophys Acta 1815: 147-157, 2011.

8. Huber O, Ménard L, Haurie V, Nicou A, Taras D and Rosenbaum J: Pontin and reptin, two related ATPases with multiple roles in cancer. Cancer Res 68: 6873-6876, 2008.

9. Polakis P: The oncogenic activation of beta-catenin. Curr Opin Gen Dev 9: 15-21, 1999.

10. Rottbauer W, Saurin AJ, Lickert H, Shen X, Burns CG, Wo ZG, Kemler R, Kingston R, Wu C and Fishman M: Reptin and pontin antagonistically regulate heart growth in zebrafish embryos. Cell 111: 661-672, 2002 .

11. Weiske $\mathrm{J}$ and Huber $\mathrm{O}$ : The histidine triad protein Hint1 interacts with Pontin and Reptin and inhibits TCF-beta-catenin-mediated transcription. J Cell Sci 118: 3117-3129, 2005

12. Rashid S, Pilecka I, Torun A, Olchowik M, Bielinska B and Miaczynska M: Endosomal adaptor proteins APPL1 and APPL2 are novel activators of beta-catenin/TCF-mediated transcription. J Biol Chem 284: 18115-18128, 2009.

13. Kim JH, Kim B, Cai L, Choi HJ, Ohgi KA, Tran C, Chen C, Chung $\mathrm{CH}$, Huber O, Rose DW, et al: Transcriptional regulation of a metastasis suppressor gene by Tip60 and beta-catenin complexes. Nature 434: 921-926, 2005

14. Etard C, Gradl D, Kunz M, Eilers M and Wedlich D: Pontin and Reptin regulate cell proliferation in early Xenopus embryos in collaboration with c-Myc and Miz-1. Mech Dev 122: 545-556, 2005 .
15. Li W, Zeng J, Li Q, Zhao L, Liu T, Bjorkholm M, Jia J and Xu D: Reptin is required for the transcription of telomerase reverse transcriptase and over-expressed in gastric cancer. Mol Cancer 9: 132,2010

16. Bellosta P, Hulf T, Balla Diop S, Usseglio F, Pradel J, Aragnol D and Gallant P: Myc interacts genetically with Tip48/Reptin and Tip49/Pontin to control growth and proliferation during Drosophila development. Proc Natl Acad Sci USA 102: 11799-11804, 2005.

17. Si J, Yu X, Zhang Y and DeWille JW: Myc interacts with Max and Miz1 to repress C/EBPdelta promoter activity and gene expression. Mol Cancer 9: 92, 2010.

18. Sun Y, Jiang X and Price BD: Tip60: connecting chromatin to DNA damage signaling. Cell Cycle 9: 930-936, 2010.

19. Tyteca S, Vandromme M, Legube G, Chevillard-Briet M and Trouche D: Tip60 and p400 are both required for UV-induced apoptosis but play antagonistic roles in cell cycle progression. EMBO J 25: 1680-1689, 2006.

20. Jha S, Shibata E and Dutta A: Human Rvb1/Tip49 is required for the histone acetyltransferase activity of Tip60/NuA4 and for the down-regulation of phosphorylation on $\mathrm{H} 2 \mathrm{AX}$ after DNA damage. Mol Cell Biol 28: 2690-2700, 2008.

21. Dugan KA, Wood MA and Cole MD: TIP49, but not TRRAP, modulates c-Myc and E2F1 dependent apoptosis. Oncogene 21: 5835-5843, 2002.

22. Haurie V, Menard L, Nicou A, Touriol C, Metzler P, Fernandez J, Taras D, Lestienne P, Balabaud C, Bioulac-Sage P, et al: Adenosine triphosphatase pontin is overexpressed in hepatocellular carcinoma and coregulated with reptin through a new posttranslational mechanism. Hepatology 50: 1871-1883, 2009.

23. Bullwinkel J, Baron-Lühr B, Lüdemann A, Wohlenberg C, Gerdes J and Scholzen T: Ki-67 protein is associated with ribosomal RNA transcription in quiescent and proliferating cells. J Cell Physiol 206: 624-635, 2006.

24. Scholzen T and Gerdes J: The Ki-67 protein: from the known and the unknown. J Cell Physiol 182: 311-322, 2000.

25. Funaioli C, Pinto C, Mutri V, Di Fabio F, Ceccarelli C and Martoni AA: Does biomolecular characterization of stage II/ III colorectal cancer have any prognostic value? Clin Colorectal Cancer 6: 38-45, 2006.

26. Kuremsky JG, Tepper JE and McLeod HL: Biomarkers for response to neoadjuvant chemoradiation for rectal cancer. Int $\mathrm{J}$ Radiat Oncol Biol Phys 74: 673-688, 2009.

27. Lauscher JC, Loddenkemper C, Kosel L, Gröne J, Buhr HJ and Huber O: Increased pontin expression in human colorectal cancer tissue. Hum Pathol 38: 978-985, 2007.

28. Wood MA, McMahon SB and Cole MD: An ATPase/helicase complex is an essential cofactor for oncogenic transformation by c-Myc. Mol Cell 5: 321-330, 2000.

29. Feng Y, Lee N and Fearon ER: TIP49 regulates $\beta$-cateninmediated neoplastic transformation and T-cell factor target gene induction via effects on chromatin remodeling. Cancer Res 63: 8726-8734, 2003.

30. Ki DH, Jeung HC, Park CH, Kang SH, Lee GY, Lee WS, Kim NK, Chung HC and Rha SY: Whole genome analysis for liver metastasis gene signatures in colorectal cancer. Int J Cancer 121: 2005-2012, 2007

31. Li W, Zeng J, Li Q, Zhao L, Liu T, Bjorkholm M, Jia J and Xu D: Reptin is required for the transcription of telomerase reverse transcriptase and over-expressed in gastric cancer. Mol Cancer 9: $132,2010$.

32. Sanchez-Carbayo M, Socci ND, Lozano J, Saint F and Cordon-Cardo C: Defining molecular profiles of poor outcome in patients with invasive bladder cancer using oligonucleotide microarrays. J Clin Oncol 24: 778-789, 2006

33. Dehan E, Ben-Dor A, Liao W, Lipson D, Frimer H, Rienstein S, Simansky D, Krupsky M, Yaron P, Friedman E, et al: Chromosomal aberrations and gene expression profiles in non-small cell lung cancer. Lung Cancer 56: 175-184, 2007.

34. Rousseau B, Menard L, Haurie V, Taras D, Blanc J, MoreauGaudry F, Metzler P, Hugues M, Boyault S, Lemiere S, et al: Overexpression and role of the ATPase and putative DNA helicase RuvB-like 2 in human hepatocellular carcinoma. Hepatology 46: 1108-1118, 2007.

35. Notaridou M, Quaye L, Dafou D, Jones C, Song H, Hogdall E, Kjaer SK, Christensen L, Hogdall C, Blaakaer J, et al: Common alleles in candidate susceptibility genes associated with risk and development of epithelial ovarian cancer. Int J Cancer 128: 2063-2074, 2011. 